\title{
UN DEPÓSITO DE PROYECTILES DE CATAPULTA HALLADO EN CALAHORRA (LA RIOJA)
}

\author{
POR \\ JOSÉ LUIS CINCA \\ Amigos de la Historia de Calahorra \\ JOSÉ LUIS RAMÍREZ SÁDABA \\ Universidad de Cantabria \\ JAVIER VELAZA \\ Universidad de Barcelona
}

PALABRAS CLAVE: Proyectiles escritos, Calahorra, guerras sertorianas, Castra Martia, Marco Lépido.

KEY WORDS: Inscribed projectiles, Calahorra, Sertorian wars, Castra Martia, Marcus Lepidus.

\section{RESUMEN}

El propósito de este trabajo es presentar el depósito de proyectiles de catapulta hallado en Calahorra (La Rioja), y analizar las hipótesis más verosímiles sobre el contexto histórico de estos documentos.

\section{RÉSUMÉ}

L'objectif de ce travail est présenter le dépôt de projectiles de catapulte trouvé à Calahorra (La Rioja) et d'analyser les hypothèses les plus vraisemblables autour du contexte historique de ces documents.

\section{CIRCUNSTANCIAS DEL HALLAZGO}

Entre los años 2000 y 2001 se llevaron a cabo excavaciones arqueológicas en un conjunto de solares ubicados entre las calles Tilos, Chavarría, José María Adán y Avenida de la Estación, en la ciudad de Calahorra (La Rioja) ${ }^{1}$. Las precarias condiciones

* Una primera presentación de estos materiales se llevó a cabo durante el XII Congreso Internacional de Epigrafía Griega y Latina, celebrado en Barcelona en septiembre de 2002. El texto de aquella aportación verá la luz en breve en las Actas de dicho Congreso, bajo el título «Avance sobre dos proyectiles de catapulta con inscripción hallados en Calahorra (La Rioja)». Como allí, agradecemos muy sinceramente al Dr. Marc Mayer que haya discutido con nosotros la lectura de los textos, así como al Dr. Luis Amela sus sugerencias en torno a la interpretación. Por supuesto, la responsabilidad última de la edición e interpretación recae en los autores.

${ }^{1}$ En el marco del proyecto «Recuperación, investigación y musealización del Casco Histórico de Calagurris Iulia», promovido por las Universidades de La Rioja, País Vasco y Murcia (vid. Iguácel de la Cruz, P., «Las fuentes arqueológicas», en Así era la vida en una ciudad romana: Calagurris de medios en las que tuvieron que desarrollarse las intervenciones y la premura de tiempo ante la inminente construcción de un centro comercial impidieron el control arqueológico de una buena parte del solar y, en consecuencia, acarrearon la destrucción de estructuras y la pérdida de un buen número de materiales que, según información de los operarios que allí trabajaban, «fueron llevados por camiones a la escombrera municipal».

Los testimonios de quienes participaron en las labores de desmonte del terreno sitúan el lugar concreto del hallazgo en la zona norte del solar junto a la calle Tilos (fig. 1). Allí se encontró «una galería de $1,50 \mathrm{~m}$, a $5 \mathrm{~m}$ de la rasante actual de la calle, en la cual se amontonaban las bolas unas encima de otras, dando la sensación de estar colocadas con intencionalidad y sin haber podido llegar a ese punto de modo casual». También por noticias orales sabemos que, cuando se desmontaron esos mismos terrenos en la primera mitad del siglo XX para la construcción de naves industriales, se hallaron «en número de varios cientos» proyectiles similares a éstos, que fueron arrojados a la cimentación de dichas naves ${ }^{2}$. Gutiérrez Achútegui describe así el hallazgo de estas piezas en el espacio comprendido entre la calle Cavas y el Paseo del Mercadal: «Frente a las Cavas, hoy todo edificado, en los solares próximos a la Basconia, también edificados, y en los desmontes que se hicieron cuando se edificó la antigua Plaza de Toros (hoy Ideal Cinema y alrededores), aparecieron con abundancia bolas de piedra arenisca, de unos $14 \mathrm{~cm}$ de diámetro, que las empleaban como proyectiles disparados con catapultas.

Iulia, Calahorra 2002, 24. Tenemos que agradecer la disponibilidad manifestada en todo momento por las personas que recuperaron los proyectiles de las escombreras, quienes, queriendo permanecer en el anonimato, nos las han facilitado para su estudio.

${ }^{2}$ Según testimonio de D. Manuel Ruiz Belloso. 


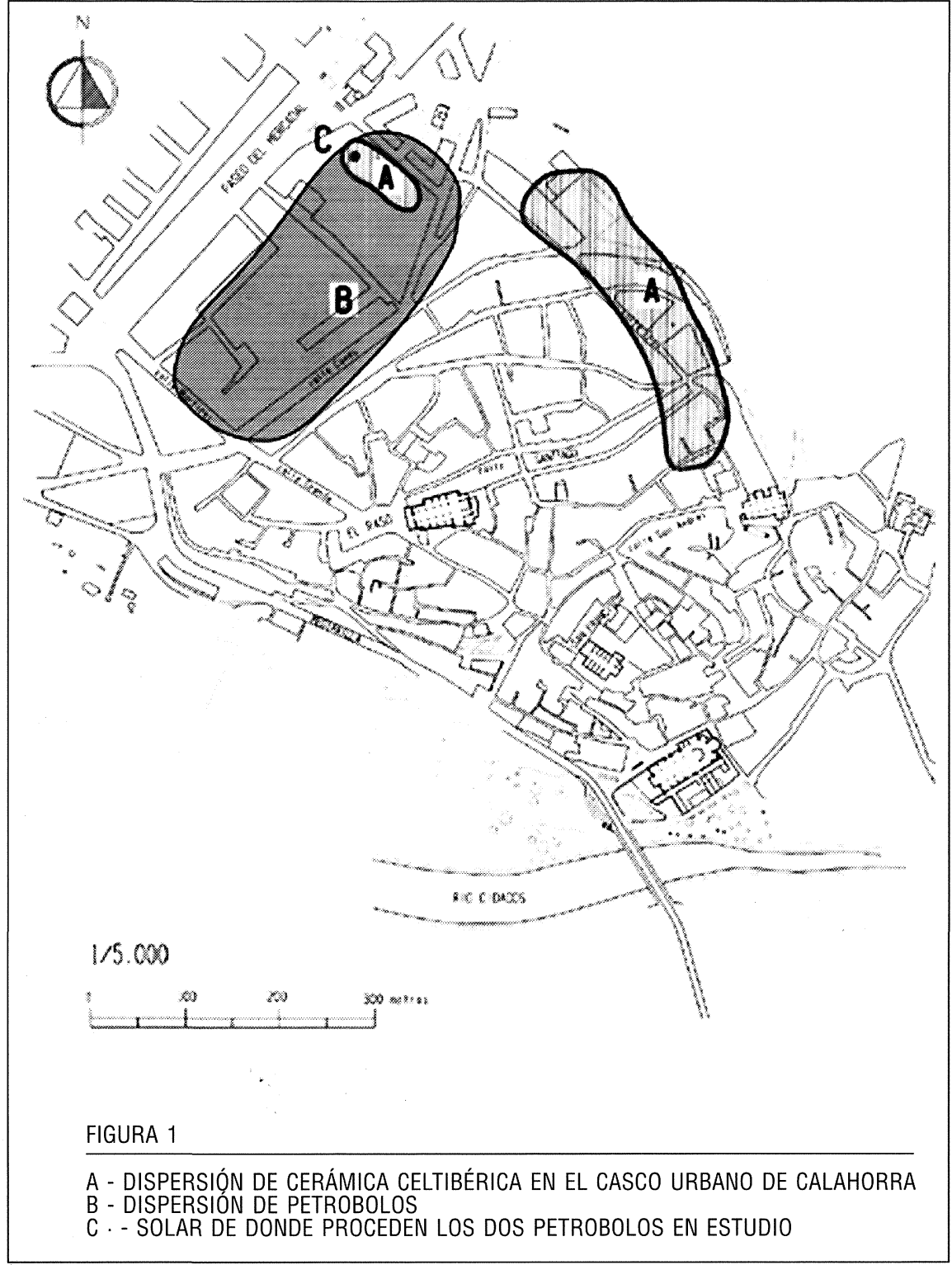

Fig. 1. Plano de la zona de hallazgo en Calahorra.

tanto, aunque las piezas que aquí estudiamos fueron recuperadas de la escombrera, el lugar concreto de procedencia está perfectamente localizado. Es imposible determinar el número de proyectiles a los que se hace referencia de forma oral o escrita en estos últimos decenios, pero sin duda podemos hablar de varios cientos.

\section{Proyectil 1}

El proyectil que denominaremos 1 tiene una forma ligeramente achatada, y su diámetro varía entre $\operatorname{los} 10$ y $\operatorname{los} 11,5 \mathrm{~cm}$ (fig. 2 y 3 ). Su estado de conservación es bueno, aunque presenta algunos golpes $\mathrm{y}$ desconchados que, sin embargo, no dificultan la lectura del texto. Las letras, de $3,5 / 5 \mathrm{~cm}$ de módulo, han sido grabadas siguiendo la circunferencia de la pieza y, por lo que parece, intentando ocuparla completamente. La ausencia de una ordi-

En nuestra infancia las empleábamos para juegos» ${ }^{3}$. También existen noticias recientes del hallazgo de nuevas piezas reaprovechadas en los muros de los edificios de la zona, y entre los materiales recuperados en las excavaciones del proyecto Calagurris Iulia también hay ejemplares aún inéditos ${ }^{4}$. Por lo

${ }^{3}$ Gutiérrez Achútegui, P., Historia de la muy noble antigua y leal ciudad de Calahorra, Logroño 1981, 23.

${ }^{4}$ Agradecemos a los integrantes del citado proyecto las informaciones que nos han facilitado sobre los materiales y resultados aún inéditos de las excavaciones llevadas a cabo en este solar. natio previa ha producido un problema de espacio en la segunda palabra, que el grabador ha solucionado reduciendo el tamaño y la separación entre los últimos signos. La paleografía corresponde a una capital de época republicana, sobre todo si juzgamos por la forma de la A, con el trazo transversal oblicuo ${ }^{5}$. Entre las dos palabras del texto se ha marcado separación en forma de interpunción triple. Este extremo

${ }^{5}$ De las cuatro A empleadas, sólo la tercera tiene el trazo transversal apoyado en el trazo izquierdo, mientras que en el resto de los casos lo tiene apoyado sobre el derecho. 


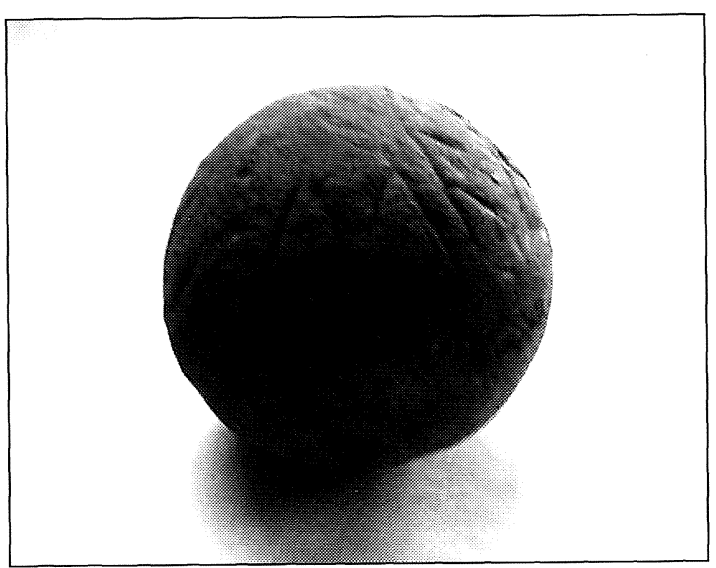

Fig. 2. Proyectil 1 (detalle).

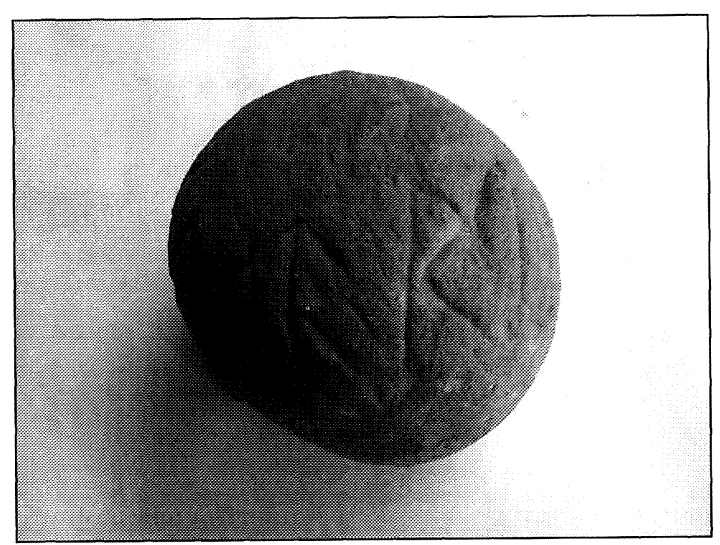

Fig. 3. Proyectil 1 (detalle).

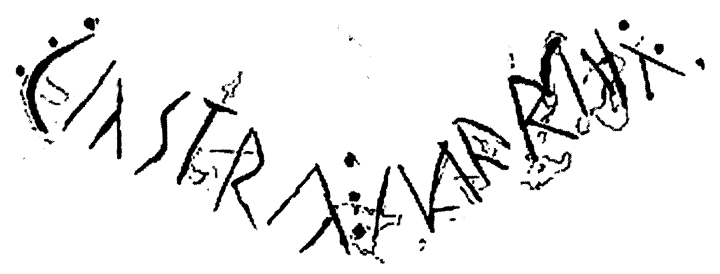

Fig. 4. Proyectil 1 (calco).

parece digno de atención, porque, si bien tal forma es muy infrecuente en epigrafía romana, resulta muy habitual en la epigrafía paleohispánica, especialmente en la del ámbito ibérico.

El texto del epígrafe puede leerse sin mayores problemas como:

\section{- castra $\bullet$ Martia}

\section{Proyectil 2}

El proyectil 2 tiene una forma casi perfectamente esférica, con un diámetro de $15 \mathrm{~cm}$ (fig. 4, 5, 6 y 7). También en este caso se ha pretendido grabar la inscripción ocupando toda la circunferencia, pero la palabra formidine ha sido escrita sobre la línea del texto, a nuestro juicio no por un mal cálculo del espacio, sino porque se trata de un pensamiento añadido posteriormente, aunque probablemente por la misma mano. Los signos tienen un módulo medio de $2 / 3 \mathrm{~cm}$, y desde el punto de vista paleográfico presentan las formas de una capital de época republicana, como lo demuestran de nuevo la forma de la $\mathrm{A}$ y, aquí además, la $\mathrm{P}$ abierta. La separación entre palabras se ha marcado con una interpunción simple a media caja. El estado de conservación de la pieza es bueno en términos generales, pero en algunos lugares el desgaste de la superficie escrita y algunos golpes y desconchados dificultan la lectura de algunos signos. Por otra parte, el hecho de que el texto corra alrededor del ecuador del soporte cubriéndolo por completo constituye un problema de cara a determinar cuál era el orden de palabras exacto. De todos modos, el problema más grave para la lectura y comprensión del texto está en la secuencia que aparece entre exerceto y fuga separada por interpunciones de dichas palabras. Después de repetidas autopsias y calcos, creemos preferible ser prudentes en este punto; a continuación se exponen las alternativas posibles con su problemática concreta:

- La hipótesis de lectura LE IV por le(gio) IV tropieza con obstáculos epigráficos muy serios. En primer lugar, a pesar de la existencia de un desconchado entre los dos primeros y los dos últimos signos, no parece haber interpunción en el interior de la secuencia, contra lo que ocurre en el resto de la inscripción de forma coherente. Pero, por lo demás, es incuestionable que el primer signo es $\mathrm{E}$; aunque aceptásemos que el segundo es L - haciendo omisión para ello del trazo horizontal superior que parece claro- quedaría por explicar cómo EL puede haberse escrito como abreviatura de legio. La hipótesis de una escritura defectiva LE por LE de le(gio) nos parece un argumento commoditatis causa muy difícil de mantener.

- De la misma manera una lectura ELIV - aun considerando adventicio nuevamente el trazo superior del segundo signo- no ofrece explicación satisfactoria en latín. No puede corresponder a una palabra del léxico común, y la interpretación como forma vulgar de Aeliu(s) o Aeliu( $m$ ) no parece tampoco coherente con el contexto de la frase.

- Una opción que no se puede descartar es que nos hallemos ante una forma arcaica del genitivo del singular eius. En inscripciones arcaicas tenemos ejemplos de reduplicación de $\mathrm{E}$ en formas del para- 


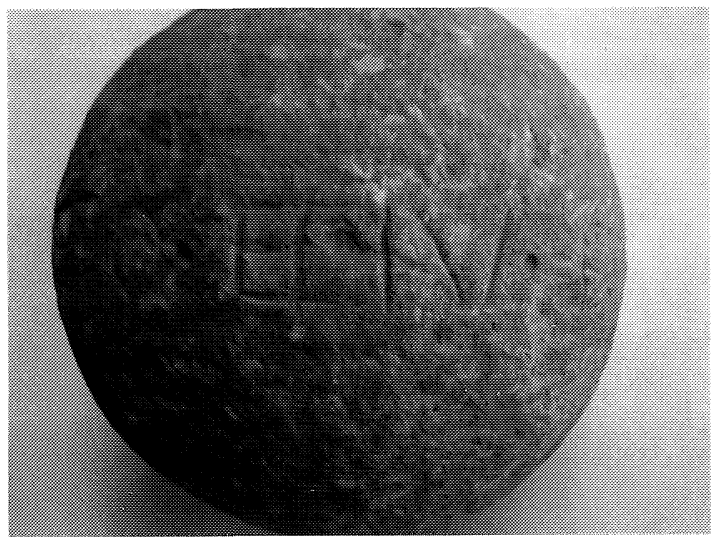

Fig. 5. Proyectil 2 (detalle).

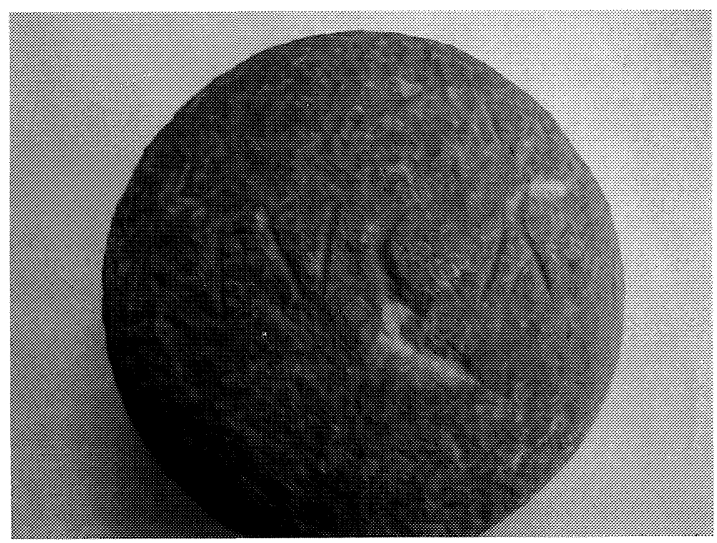

Fig. 6. Proyectil 2 (detalle).

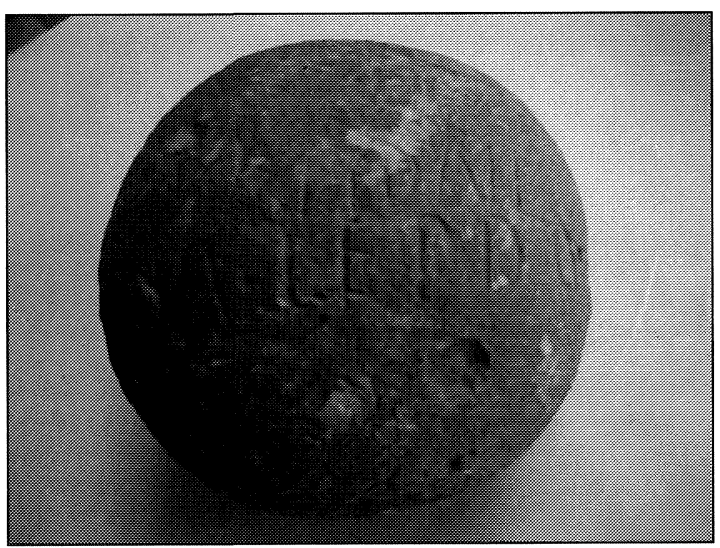

Fig. 7. Proyectil 2 (detalle).

digma de $i s^{6}$, así como de caída de $-s$ en posición final ${ }^{7}$.

${ }^{6}$ Vid. Sommer, F., Handbuch der lateinischen Laut- und Formenlehre, Heidelberg 1914³, 417-419.

7 Sobre la debilidad de $-s$ en este periodo, véanse, entre otros, Niedermann, M., Phonétique historique du latin, París

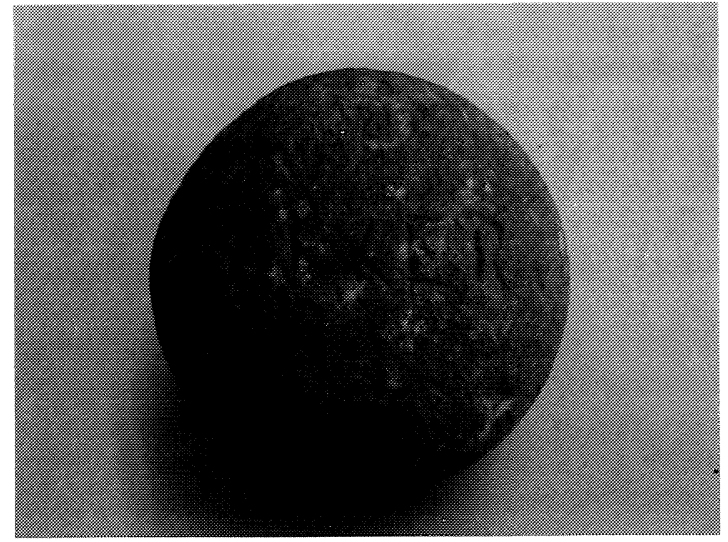

Fig. 8. Proyectil 2 (detalle).

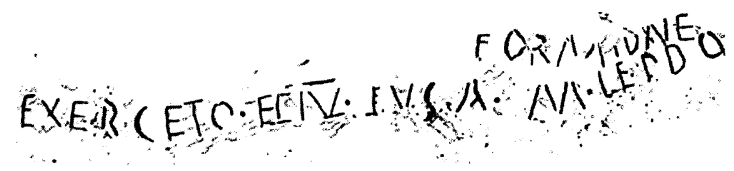

Fig. 9. Proyectil 2 (calco).

De todos modos, ante las dificultades que ofrecen todas estas soluciones, consideramos más prudente ofrecer una edición aséptica y no comprometida como la que sigue:

\section{exerceto $\bullet$ EEIV $\bullet$ fuga $\bullet M($ arco $) \bullet \operatorname{Lep}(i) d o \bullet$ formidine}

Desde un punto de vista lingüístico conviene destacar la grafía LEPDO por LEPIDO, que sin duda responde a una síncopa, fenómeno bien atestiguado en el latín de la época ${ }^{8}$. Además, si fuga está por fugam, como parece lo más verosímil ${ }^{9}$, nos encontraríamos con el fenómeno bien conocido de la no notación de $-m$ en posición final.

1940, Devoto, G., Storia della lingua di Roma, Roma 1983 (reimpr. anast.), vol.. II, 107, Corssen, W., Über Aussprache, Vokalismus und Betonung der lateinischen Sprache, Leipzig 18682, 286-294, Proskauer, C., Das auslautende s auf den lateinischen Inschriften, Estrasburgo 1910, Sullivan, J.B., Final $-s$ in early Latin, Diss. Yale Univ., New Haven 1970.

${ }^{8}$ Véase, por ejemplo, Devoto, G., op. cit., vol. I, 107 y Rix, S., «Die lateinische Synkope», Kratylos 11, 1966, 156165. En la palabra FORMIDINE el primer trazo de la letra $\mathrm{N}$ y la I se cruzan. Aunque el fenómeno pudiera hacer pensar en un nuevo caso de síncopa rectificada, no es así, puesto que una atenta autopsia pone de manifiesto que la I fue grabada con anterioridad, aunque con una orientación un tanto desviada de la hipotética caja de la escritura, de forma que la superposición de $\mathrm{N}$ responde sólo a la voluntad de recuperar la orientación correcta.

${ }^{9}$ La hipótesis de que fuga sea un imperativo del verbo fugo nos parece menos probable por razones sintácticas. 


\section{Proyectiles con numerales ${ }^{10}$}

Entre los 314 proyectiles que han podido ser estudiados, veintiocho llevan inscripciones de carácter numeral (figs. 8, 9, 10, 11 y 12). En el cuadro siguiente se recogen de manera esquemática el diámetro, el peso y la inscripción que porta cada una de estas piezas:

\begin{tabular}{|c|c|c|c|}
\hline Proyectil & $\begin{array}{c}\text { Diámetro } \\
\text { (en cms) }\end{array}$ & $\begin{array}{c}\text { Peso } \\
\text { (en kgs) }\end{array}$ & Inscripción \\
\hline 3 & 14 & 3,50 & IIII (?) \\
\hline 4 & 15 & 5,50 & IV /X \\
\hline 5 & 17 & 7,00 & V (?) \\
\hline 6 & 18 & 6,00 & VX (?) \\
\hline 7 & 23 & 14,00 & VX (o XIV) \\
\hline 8 & 15 & 4,50 & $\mathrm{X}$ \\
\hline 9 & 14 & 3,25 & $\mathrm{X}(\mathrm{I} ?)$ \\
\hline 10 & 15 & 3,60 & $\mathrm{XI}$ \\
\hline 11 & 16 & 4,60 & XI (?) \\
\hline 12 & 22 & 14,00 & XIIII \\
\hline 13 & 16 & 4,50 & XIII \\
\hline 14 & 16 & 4,00 & XIIII \\
\hline 15 & 15 & 3,50 & XIV \\
\hline 16 & 16 & 5,50 & $\mathrm{XV}$ \\
\hline 17 & 17 & 5,30 & XVIIII \\
\hline 18 & 19 & 6,00 & XIIX \\
\hline 19 & 22 & 10,00 & $\mathrm{XX}$ \\
\hline 20 & 20 & 7,50 & $\mathrm{XX}$ \\
\hline 21 & 17 & 4,60 & $\mathrm{XX}$ \\
\hline 22 & 17 & 6,00 & $\mathrm{XX}$ \\
\hline 23 & 15 & 4,50 & $\mathrm{XX}$ \\
\hline 24 & 20 & 7,00 & XXI \\
\hline 25 & 18 & 6,50 & XXII \\
\hline 26 & 20 & 8,00 & $\mathrm{XXV}$ \\
\hline 27 & 19 & 8,00 & XXVI \\
\hline 28 & 24 & 14,00 & XXXXII \\
\hline 29 & 16 & 5,00 & (?) \\
\hline 30 & 17 & 5,25 & 4 \\
\hline
\end{tabular}

Un aspecto de gran interés, sin duda, pero para el que no tenemos por el momento una solución definitiva, es el del significado exacto de estas marcas. Como puede observarse, no existe una correlación directa entre el numeral inscrito y el peso o el diámetro de la pieza, de forma que parece descartable una interpretación como indicación metrológica. Por otro lado, el gran número de cifras diferentes documentadas en el depósito parece que dificulta la interpretación como referencia a las unidades militares. Así las cosas, quizás haya que contemplar la posibilidad de que el número corresponda al de la catapulta para el que estaba destinada la pieza o, sin más, a

${ }^{10}$ Agradecemos a José Manuel Domínguez y a Carmen Cinca su colaboración en el inventario de los proyectiles.

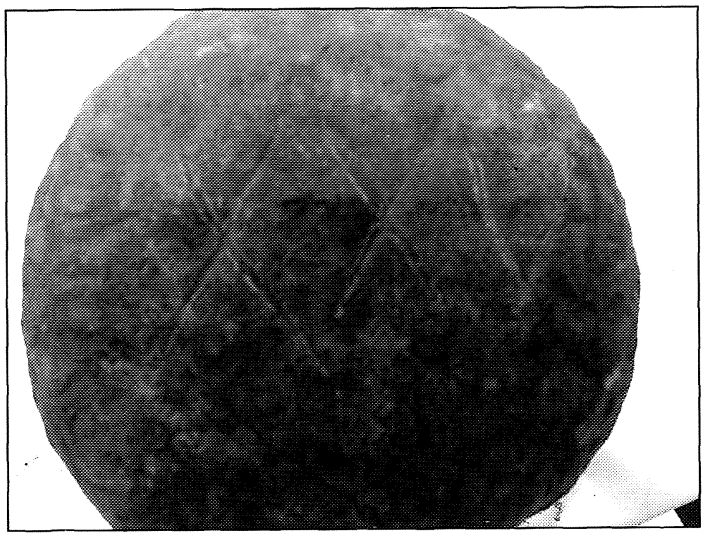

Fig, 10. Proyectil 26 (cifra XXV).

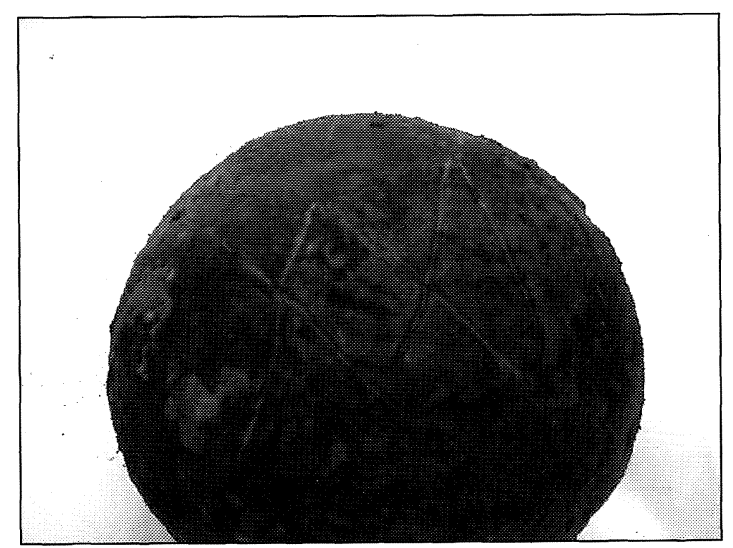

Fig. 11. Proyectil 24 (cifra XXI).

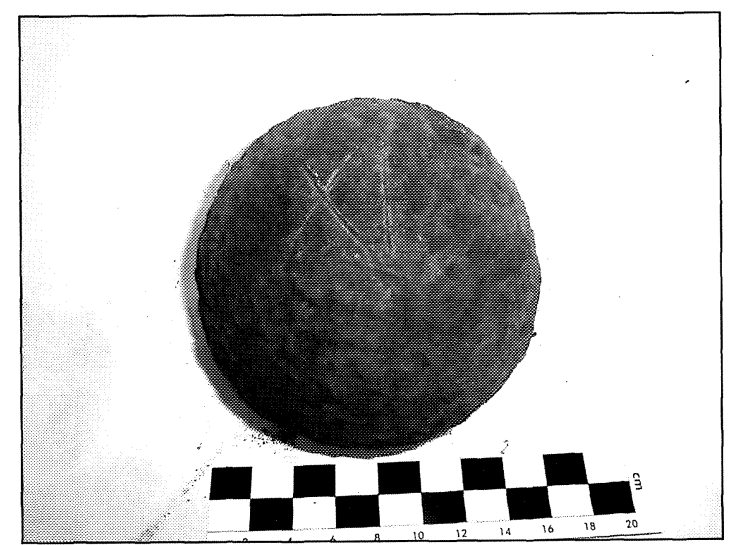

Fig. 12. Proyectil 10 (cifra XI).

la cantidad de «tarea» hecha por el tallador en una o varias jornadas. En este sentido, no deja de ser interesante que la pieza número 30 (fig. 13) lleve inscrito un signo celtibérico ti, lo que puede ser índice de la participación de celtíberos en las tropas de asedio. 


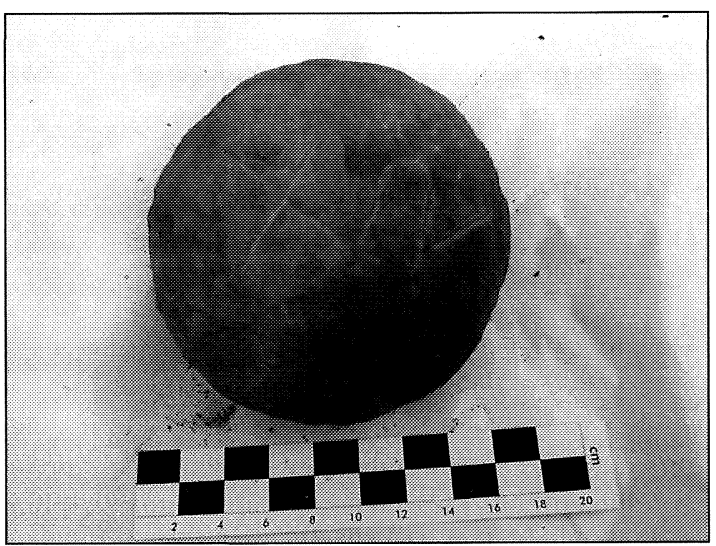

Fig. 13. Proyectil 15 (cifra XIV).

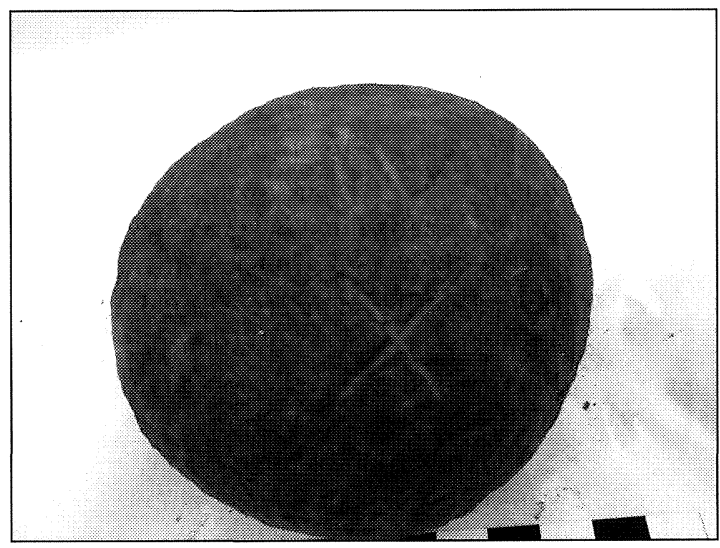

Fig. 14. Proyectil 4 (cifras IV y X).

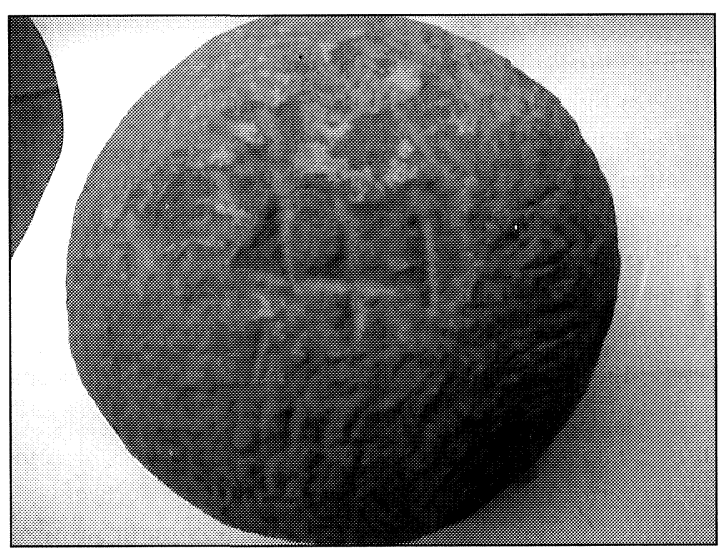

Fig. 15. Proyectil 30 (signo celtibérico ti).

\section{CUESTIONES HISTÓRICAS}

La interpretación de la mención de unos castra Martia requiere algunas reflexiones históricas que aquí solamente pretendemos esbozar. En primer lu- gar, consideramos que debe ponerse en relación con la legio Martia, para la que contamos con numerosas noticias contenidas, en su mayor parte, en las Filípicas de Cicerón ${ }^{11}$.

Evidentemente, el dato más elocuente con el que contamos para situar las piezas en su contexto histórico no es otro que el de la mención de Marco Lépido en el proyectil n. 2. Sin embargo, no es evidente si se trata del cónsul de época sertoriana o del triunviro. Ambos personajes actúan en Hispania en el último siglo de la república romana, momento al que corresponden los proyectiles según se ha explicado ya al comentar los rasgos paleográficos. Para tratar de dilucidar a cuál de los dos corresponden son necesarias las siguientes reflexiones:

- Marco Lépido, el triunviro. Vino a Hispania Citerior el 48 a. C. con el cargo de procónsul, pero en este momento la provincia estaba ya pacificada, o al menos sometida a la autoridad de César ${ }^{12}$. Afranio, el legado pompeyano que la había tenido a su cargo, estaba ya en Dyrrachium junto a Pompeyo ${ }^{13}$. En el 47 a. C. Lépido regresó a Roma y celebró el triunfo, pero no por operaciones bélicas en Calagurris, sino por haber ayudado a Longino y Marcelo en la Hispania Ulterior ${ }^{14}$. En el 44 volvió Lépido como procónsul a la Citerior y consiguió que Sexto Pompeyo abandonara las armas ${ }^{15}$, por lo que fue

${ }^{11}$ La mención de unos castra Martia en Tibulo I, 2 (ille licet Cilicum uictas agat ante cateruas, / ponat et in capto Martia castra solo) debe ser rechazada como paralelo, porque se trata de una expresión metafórica. Las noticias de $\mathrm{Ci}$ cerón en torno a la legio Martia son Phil. IV, 5 y 6, XIII, 18, 19, 20 y 33; XIV, 26, 27 y 31. Además, hay referencias en Veleyo Patérculo 2, 61 y Dión Casio 45.

12 Para Lépido y su carrera pueden verse en general los trabajos de Weigel, D., Lepidus, London-New York 1992, y de Wald, H. E., "The Career of M. Aemilius Lepidus 49-44 BC», Hermes 123, 1995, 443-454. Sobre las actividades de Lépido en Hispania, véase ahora Amela, L., «Lépido en Hispania», Hant 26, 2002, 8-31; también Idem, «La conspiración contra Casio Longino», $R H M$, en prensa (reiteramos nuestra gratitud al Dr. Amela por habernos informado sobre este trabajo en prensa).

${ }_{13}$ Para todos los cargos que se mencionan a continuación y sus fuentes respectivas, véase Broughton, T.R.S., The $M a-$ gistrates of the Roman Republic, Vol. II, Atlanta 1984 (2. ed.). Para los cargos de Lépido y Afranio en el año 48, véanse las pp. 275 y 280 respectivamente.

${ }_{14}$ Cass. Dio, 43.1.: "Después que César fue nombrado, por primera vez, dictador, mandó a Lépido a la Hispania $C i$ terior, una vez concluida su pretura [año 48], y a su regreso le honró con el triunfo, aunque ni había vencido a nadie ni había disputado el mando con nadie, sino con el pretexto de que había ayudado a los que vencieron con Longino y a los que vencieron con Marcelo. Consiguientemente no envió nada para acreditarlo, excepto el dinero que había robado a los aliados».. Es evidente que no sostuvo ningún combate, y menos en Calagurris. Para la supplicatio cf. Phil. 3.23-24. A la misma conclusión llega Amela Valverde, L., «Lépido en Hispania», HAnt 26, 2002, 37-38 y 40-41.

${ }^{15}$ Cf. Broughton, T.R.S., l.c., 326. 
aclamado imperator, recibió una supplicatio y una estatua ecuestre en Roma y celebró el triunfo ${ }^{16}$, pero tampoco hay datos para pensar en una campaña militar en Calagurris por dos motivos: ni se conoce ninguna relación entre Lépido y Calagurris, ni hay razones para suponer que Lépido hubiera podido ser encerrado en esta ciudad por Sexto Pompeyo ${ }^{17}$. Y es evidente que las balas iban dirigidas contra alguien que sufría asedio dentro de los muros calagurritanos. Tras la batalla de Módena (43 a. C.) a Lépido le correspondieron la Galia Transalpina e Hispania, pero gobernó por medio de legados, no volvió a la península ni hubo actividades bélicas en ella ${ }^{18}$.

- Marco Lépido, el cónsul coetáneo de la guerra sertoriana. Lépido pertenecía a la facción antisilana y fue elegido cónsul para el año 78 a.C. Había prometido devolver a los itálicos las tierras que Sila les había confiscado, y el Senado, receloso, le hizo venir a Roma desde la Galia Transalpina. Volvió con el ejército, se enfrentó a Cátulo y fue derrotado en el año 77. Huyó a Cerdeña, donde murió, y la mayor parte de su ejército fue conducida a Hispania por Perpenna, quien lo puso bajo las órdenes de Sertorio ${ }^{19}$, el líder de la única facción antisilana que aún se mantenía operativa y victoriosa. Precisamente para terminar con ella el Senado acababa de mandar a Hispania a Pompeyo, cuyo primer enfrentamiento con Sertorio tuvo lugar el año 76 en Lauro, en tierras del Levante.

\section{El asedio de Calagurris en el marco de las guerras sertorianas}

Éste es, pues, el contexto en que podemos situar las balas, el nombre de Marco Lépido y el asedio de Calagurris $^{20}$. En el año 74 Pompeyo y Metelo se

\footnotetext{
${ }^{16}$ Amela Valverde, L., l. c., 44-48.

${ }^{17}$ Precisamente el texto de Cicerón alaba la actitud conciliadora de Lépido en Phil. 5.40-41: «Cum a M. Lepido imperatore ... eius opera, virtute, consilio singularique clementia et mansuetudine bellum acerbissimum civile sit restinctum ... senatum populumque romanum pro maximis plurimisque in rem publicam meritis ... statuam equestrem inauratam in rostris aut quo loco in foro vellet ex huius ordinis sententia statui placere».

${ }_{18}$ Cf. para todo este proceso Amela Valverde, L., l. c., 50-53.

${ }^{19}$ App., b.c., I, 105-107.

${ }^{20}$ Para el desarrollo de la guerra véase García Morà, F., Un episodio de la Hispania Republicana: La Guerra de Sertorio, Granada 1991. Los asedios de Calagurris están tratados con más detalle por Espinosa, U., Calagurris Iulia, Logroño 1984. Para un análisis más profundo del valor e interpretación de las fuentes, véase Ramírez Sádaba, J. L., «Limitaciones inherentes a las fuentes literarias: Consecuencias de la guerra sertoriana para Calagurris», Gerión, 3, 1985, 231-243.
}

encuentran asediando la ciudad. Ignoramos con qué fuerzas se defendía, pero evidentemente eran sertorianas, quizá parte de los «lepidanos» traídos por Perpenna. Fue Sertorio el que obligó a los generales senatoriales a levantar el asedio causándoles 3.000 bajas ${ }^{21}$. Pompeyo y Metelo eran los generales «legítimos»; Sertorio y los lepidanos, «rebeldes». Pero puede resultar extraño que se mencione a Marco Lépido, que había muerto hacía tres años. Naturalmente la bala no podía ir contra Sertorio, porque no estaba en la ciudad; tenía que ir contra los otros rebeldes, contra los lepidanos encarnados en su jefe. A este respecto puede resultar ilustrativo cómo se conservaba el recuerdo de Lépido. Al año siguiente, el 73, se promulga la Lex Plautia de redditu Lepidanorum $^{22}$. Es decir, no se menciona a Perpenna ni a Sertorio; se menciona a los lepidanos. Evidentemente se trata de una maniobra política, pero en la que se tenía una consideración especial con las tropas de Lépido, quizá porque se podían calificar como «tropas legítimas romanas» puestas en rebeldía por Lépido y a las que se quería indultar ${ }^{23}$. En otras palabras; no se había olvidado que el enemigo era, y había sido, Marco Lépido. Desde este punto de vista podría explicarse el nombre de Marco Lépido en la bala; su ejército iba vinculado a su nombre y contra él, como si fuera un omen, iba el proyectil ${ }^{24}$.

Dada la configuración topográfica de la ciudad, el lugar del hallazgo es el más idóneo para intentar su asalto y conquista, y, por lo tanto, el adecuado

${ }^{21}$ Cf. App., b.c., I, 112.

22 Para los problemas de datación consúltese García Morà, F., $l$. c., 339-340. En nuestra opinión la ley fue promulgada el año 73 a.C.

${ }^{23}$ Precisamente un poco antes del asedio de Calagurris, pero en el transcurso del mismo año, muchos sertorianos habían hecho defección pasándose al campo de Metelo. Tal vez se quiso aprovechar el descontento para crear la confusión y el desánimo entre las tropas asediadas mandándoles mensajes con las propias balas.

${ }^{24}$ Calagurris aún sufrió otro asedio en el año 72 a. C. y los proyectiles podrían corresponder a este último. La argumentación sería la misma, pero es más verosímil que correspondan al primer asedio. En el año 72 Afranio no necesitaba que los lepidanos huyesen. Ya no tenían a dónde huir. Pero si hubieran huido en el 74 habrían dejado en manos de Pompeyo y Metelo una ciudad estratégica. Pensamos además que algunos lepidanos se habían beneficiado de la Ley Plautia. No tendría sentido hablar de redditus después del 72. ¿Dónde se podrían haber refugiado después de la victoria de Pompeyo?. Consecuentemente, si en el 72 quedaban lepidanos en Calagurris serían los recalcitrantes a los que Afranio no iba a dar oportunidad de huir. Estas consideraciones nos llevan a pensar que las balas fueron fabricadas durante el asedio del año 74 a. C., y que quedaron abandonadas cuando Metelo y Pompeyo levantaron precipitadamente el asedio. Pero también hay que dejar abierta la duda de que no se recuperasen y utilizasen después en el asedio del 72. ¿Fueron quizá excedentes entre los que quedó alguna bala de las que se fabricaron para el asedio del 74 ? 
para el depósito de balas que ahora estudiamos y para los numerosos hallazgos habidos en el espacio entre las calles Cavas, Mártires, Mercadal y Tilos, comentado al comienzo del artículo. La línea marcada por la calle Cavas, en dirección tanto hacia La Clínica como hacia la Cuesta del Río, sigue siendo testimonio vivo de la topografía de la antigüedad ${ }^{25}$, y sobre la cual se levantó hasta la edad moderna la muralla que permitía la defensa de la ciudad en ese sector, el más desprotegido y por donde las tropas pompeyanas intentarían el asalto sirviéndose de la poliorcética de la época, de la que las balas de piedra son testimonio. El resto del cerro, con fuertes pendientes hacia el río Cidacos y hacia las terrazas de la ribera del Ebro, era prácticamente inexpugnable.

\section{La propaganda política}

No conocíamos hasta el momento ejemplos de proyectiles de catapulta con inscripción romana en Hispania ${ }^{26}$. Pero conocemos abundantes epígrafes sobre proyectiles de honda que mencionan a Sertorio o a Metelo.

Con la leyenda $Q$ Ser (o Sertor) / procos hay varios ejemplares ${ }^{27}$, en los que resaltan significativamente estos dos aspectos:

- El amplio espacio geográfico en el que se documentan las glandes: los confines bético-lusitanos (provincia de Huelva), el territorio celtibérico (provincia de Guadalajara) y valle del Ebro (provincias de Huesca y Navarra). Es decir, han proporcionado proyectiles con inscripción los principales espacios en los que combatió -Sertorio (únicamente falta el Levante).

${ }^{25} \mathrm{El}$ desnivel de dicha línea con respecto al Mercadal supera los 10 metros. Cuando a comienzos de los años 90 se construyó un aparcamiento en la calle del Teatro, salieron a la luz restos arqueológicos a $4 \mathrm{mts}$. de profundidad. Esta calle está a una cota de 3 o 4 metros por debajo de la calle Cavas y ésta, a su vez, otros tres por debajo de la calle del Sol (por donde iba la muralla, cuyos fosos son la actual calle Cavas).

${ }^{26}$ El único caso que hemos podido registrar procede de Botorrita, pero se trata de una inscripción en caracteres ibéricos con texto nai (vid. Díaz, M. A.; Jordán, C., «Grafitos procedentes de Contrebia Belaisca», Palaeohispanica 1, 2001, pp. 301-33, n. 1).

${ }^{27}$ Domínguez, A., et alii, Carta Arqueológica de Huesca, Zaragoza 1984, p. 160 y lám. 40; Chic, G., «Q. Sertorius, proconsul», Epigrafía hispánica de época romano-republicana, Zaragoza 1986, 171-176; Beltrán, F., «La pietas de Sertorio», Gerión 8, 1990, 211-226; Abascal, J. M., «Inscripciones inéditas y revisadas de la Hispania Citerior», AEspA 63, n 161-162, 1990, pp. 264-275; García Morá, F., l. c., 102; Cf. Abascal, J. M.; Gimeno, H., Epigrafía Hispánica, Catálogo del Gabinete de Antigüedades de la RAH, Madrid 2000, n. 188;
- Se ha difundido un mensaje político con los términos ius (en Guadalajara, cf. Abascal-Gimeno $2000, n^{\circ} .188$ ) y pietas (en las proximidades de Pamplona, cf. Beltrán 1990, 213), cuestión sobre la que volveremos después.

Pero también hay proyectiles con la leyenda $Q$. Me y $Q$. Met. La cantidad más importante procede de Azuaga (Badajoz), pero a juzgar por su número (1.900 aproximadamente) y las circunstancias del hallazgo (apilados en capas, «puestos como huevos»), hay que pensar que no serían los únicos proyectiles ni el único frente en que se utilizaron ${ }^{28}$.

Es decir; los dos bandos utilizaron el mismo sistema de propaganda política y en ella se insertan las balas calagurritanas. Sertorio lo puso en práctica en el frente lusitano (previsiblemente durante los años $79-76$ a. C.) y por esas mismas fechas hizo lo mismo Metelo ${ }^{29}$. En el valle del Ebro continuó Sertorio la misma estrategia durante los años $77-74{ }^{30}$, y lo mismo hicieron Metelo-Pompeyo durante el asedio de Calagurris, ya en el año 74 a.C. Incluso los términos que cada bando emplea son sumamente clarificadores, y son las balas de Calahorra un precioso instrumento para comprender la situación política y bélica. Sertorio utiliza un término jurídico (ius) y otro político-religioso (pietas), por lo que ambos «deben considerarse uno más de los mensajes políticos [que emplea] en defensa de su legitimidad» ${ }^{31}$. Metelo y Pompeyo no necesitan de dichos términos: ellos representan el poder legítimo, puesto que han sido enviados por el Senado para combatir a Sertorio. En Calagurris se utilizan términos bélicos alusivos a la situación del momento: el más significativo es el de la bala cuyo mensaje es «infundir temor para provocar la huida del ejército sertoriano».

Beltrán ha explicado el empleo del término pietas en un momento crucial para la guerra. Se trataba

${ }^{28}$ Uno de nosotros ha visto cuatro glandes conservadas en el MAP de Badajoz con $\mathrm{n}^{\circ}$ de inventario, 4.256, 11.964, 11.973 y 11.873 . Las tres primeras proceden de la colección Calzadilla, quizá parte de las muchas halladas en Azuaga (= CIL II $2 / 7,885$ ), donde se encontró un verdadero almacén de suministro; cf. Domergue, C., «Un temoignage sur l'industrie minière et métallurgique du plomb dans la région d'Azuaga (Badajoz) pendant la guerre de Sertorius», CAN 11, 1968, 608-632. Este tipo de proyectiles siguió usándose en guerras posteriores: cf. Perea, S., «Dos nuevas glandes inscriptae de la provincia de Córdoba», Homenaje al profesor A. Montenegro, Valladolid 1999, 553-560 (= CIL II $\left.{ }^{2} 5,473\right)$, donde da la noticia de varios proyectiles usados en la guerra civil, concretamente en el año 45 a.C. También en Osuna se han encontrado varios: dos de la guerra civil entre César y los hijos de Pompeyo (CIL II2/5, 1102 y 1103), otro probablemente de la guerra sertoriana (CIL II $2 / 5,1104)$ y otros dos más difíciles de identificar (CIL II2/5, 1105 y 1106).

${ }^{29}$ Domergue, C., l. c., 611-617.

${ }^{30}$ Beltrán, F., l. c., pp. 224-226

${ }^{31}$ Abascal, J. M.; Gimeno, H., l. c., n. 188 
del momento más difícil de Pompeyo, puesto que había sido vencido en Lauro, herido en Sucro, y tenía problemas de aprovisionamiento. Sertorio lanzaba un mensaje subliminal a las tropas senatoriales: la pietas significaba el respeto al régimen político legítimo que él representaba, porque Sila se había impuesto por medio de la dictadura ${ }^{32}$. Todo esto ocurría entre el 76 y el 74 a.C., pero en este último año la situación había cambiado. Pompeyo había reforzado su posición y Sertorio sufría las primeras

${ }^{32}$ Beltrán, F., l. c., pp. 225-226. deserciones (Apiano I, 111), por lo que el mensaje de las balas es claro y oportuno: se trata ahora de minar la moral de las tropas sertorianas, ya menos eufóricas y más desunidas. De ahí la mención al campamento y la propaganda destinada a quebrantar la moral formidine. Naturalmente, el tipo de propaganda era el de siempre, pero el tipo de combate distinto; en Calagurris había que derruir poderosas murallas y no servían glandes de 40/44 mm. de diámetro y 45/55 gramos de peso. Aquí eran necesarias balas de catapulta de las características que ya hemos descrito.

\section{CUADRO CRONOLÓGICO DE LOS DOS GENERALES LLAMADOS MARCO EMILIO LÉPIDO QUE TUVIERON RELACIÓN CON HISPANIA}

Año 78 a. C. : Muerte de Sila, M. Emilio Lépido, cónsul.

Año 77 a. C.: M. Emilio Lépido, procónsul en Galia Transalpina: muere Perpenna lleva su ejército a Hispania, que decide unirse a Sertorio.

Año 76 a.C.: Pompeyo ataca a Sertorio en Lauro. Vencido, retrocede a sus cuarteles de invierno en los Pirineos.

Año 75 a. C.: Pompeyo combate en Sucro. Se retira a invernar en territorio vascón.

Año 74 a. C.: Pompeyo y Metelo asedian Calagurris. Sertorio les obliga a retirarse.

Año 72 a. C.: Afranio, lugarteniente de Pompeyo, toma los últimos reductos sertorianos, entre ellos $\mathrm{Ca}$ lagurris.

Año 49 a. C. : M. Emilio Lépido, pretor al cargo de Roma.

Año 48 a. C.:M. Emilio Lépido, procónsul en la Hispania Citerior. Afranio, lugarteniente de Pompeyo, combate en Dyrrachium, junto a Pompeyo.

Año 47 a. C.: M. Emilio Lépido, procónsul de la Citerior, regresa a Roma: celebra el triunfo ex Hispania.

Año 46 a. C.: M. Emilio Lépido cónsul. Se ignora quién fue procónsul de la Citerior.

Año 45 a. C.: M. Emilio Lépido maestro de caballería. Se ignora quien fue procónsul de la Citerior.

Año 44 a. C.: M. Emilio Lépido procónsul de la Citerior: pacta con Sexto Pompeyo.

Año 43 a. C.: M. Emilio Lépido triunviro: Batalla de Módena. Manda la Citerior mediante un legado. Triunfa ex Hispania.

Año 42 a. C.: M. Emilio Lépido cónsul y triunviro: gobierna la Galia Transalpina e Hispania. Batalla de Philippi.

Año 41 a. C.: Octaviano recibe Hispania y Lépido las dos provincias de Africa. Lépido ya no volverá a tener jurisdicción sobre Hispania. 